\title{
The influence of the HAZ softening on the mechanical behaviour of welded joints containing cracks in the weld metal
}

\author{
D.M. Rodrigues *, L.F. Menezes, A. Loureiro \\ Departamento de Engenharia Mecânica, Universidade de Coimbra, Pólo II-Pinhal de Marrocos, Coimbra 3030, Portugal \\ Received 26 February 2002; received in revised form 3 June 2003; accepted 30 September 2003
}

\begin{abstract}
The mechanical behaviour of welds containing cracks was analysed through the numerical simulation of the threepoint bending tests of welded specimens. This paper presents the mechanical model and the methodology used for the numerical simulation of the tests. The variation in crack driving force of cracked welds is studied as a function of the strength mismatch in the heat affected zone and of the crack position relative to the weld metal/heat affected zone interface. This analysis was performed with recourse to the numerical calculation of the $J$ integral.
\end{abstract}

(C) 2003 Elsevier Ltd. All rights reserved.

Keywords: Elastoplasticity; Crack-driving force; Numerical simulation; Weldments; Heat affected zone

\section{Introduction}

In any weld produced with a fusion process, the mechanical properties in the heat affected zone (HAZ) can drastically differ from the unaffected base metal (BM), depending on the heating and cooling conditions imposed by the welding process and on the structure and chemical composition of the base plate. This is common in high strength steels in which slow cooling rates can cause a considerable loss in the yield strength of the base plate [1,2]. In this context, it is important to understand the effect of HAZ strength loss in the overall mechanical behaviour of the welds, in order to predict its strength and toughness. However, most of the published studies on the mechanical behaviour of welds have neglected the effect of the HAZ. They consider the welds as a bi-material system constituted by the weld metal (WM) and base metal, or were focused only in very specific situations in which the HAZ is considered as a very narrow portion of material with a precise mismatch level. There are few extensive studies concerning the variation of the weld fracture strength for a wide range of mismatch conditions and HAZ widths. In the present work, the influence of HAZ softening on the crack driving force of welds, with cracks in the weld metal centreline, is

\footnotetext{
${ }^{*}$ Corresponding author. Fax: +351-239-790-701.

E-mail address: dulce.rodrigues@dem.uc.pt (D.M. Rodrigues).
} 
evaluated. This study was performed through the numerical simulation of three-point bending tests (TPB), using finite element meshes representing samples with various weld dimensions and two different crack length sizes $(a)$. The influence of material mismatch on the crack driving force was studied by simulating various hypothetical HAZ materials for each type of sample. The numerical simulations were performed with the finite element program EPIM3D (elastoplastic implicit 3D) developed to solve problems that involve large elastoplastic transformations [3].

\section{Material modelling and numerical procedures}

\subsection{Material properties}

The mechanical model used in the code is based on the elastoplastic behaviour of materials that exhibit isotropic and kinematic work-hardening. To describe the elastic behaviour of the material, the hypoelastic form of Hooke's law, valid for arbitrary large rotations, is used. The plastic behaviour is described by the general quadratic yield condition

$$
f(\bar{\sigma}, Y)=\bar{\sigma}-Y(h)=0
$$

with an associated inviscid flow rule. In Eq. (1), $\bar{\sigma}$ is the Hill's equivalent stress and $Y(h)$ is the flow stress. In the absence of kinematic work-hardening, $\bar{\sigma}$ is defined by the quadratic form

$$
\bar{\sigma}^{2}=F\left(\sigma_{22}-\sigma_{33}\right)^{2}+G\left(\sigma_{33}-\sigma_{11}\right)^{2}+H\left(\sigma_{11}-\sigma_{22}\right)^{2}+2 L \sigma_{23}^{2}+2 M \sigma_{13}^{2}+2 N \sigma_{12}^{2},
$$

where $F, G, H, L, M$ and $N$ are material constants. The isotropic Swift work-hardening law,

$$
Y\left(\bar{\varepsilon}^{p}\right)=C\left(\varepsilon_{0}+\bar{\varepsilon}^{p}\right)^{n}
$$

describes the evolution of the flow stress $h$ with progressive deformation. In this equation, $\bar{\varepsilon}^{p}$ is the equivalent plastic strain and $n, C$ and $\varepsilon_{0}$ are material constants, $n$ being the hardening coefficient.

In this study, the mechanical behaviour of the materials was considered isotropic $(F=G=H=0.5$ and $L=M=N=1.5$ in Eq. (2)) and similar elastic properties were adopted for all weld zones $(E=200 \mathrm{GPa}$ and $v=0.33$ ). In order to cover a large range of mismatch conditions that can be expected in real welds, simulations were performed using several hypothetical values for the yield stress $\left(Y_{0}=C \varepsilon_{0}^{n}\right)$ and for the hardening coefficient $(n)$ of the HAZ material. Since the main purpose of this investigation is to study the influence of HAZ softening on the crack driving force in the defective WM, this zone was represented as a homogeneous material with lower mechanical properties than the adjacent materials (WM and BM). For the WM and BM, the same high strength mechanical properties were considered, representing an evenmatch weld with $700 \mathrm{MPa}$ yield stress and hardening coefficient, $n=0.08$. Fig. 1 presents the stress-strain curves plotted according to Eq. (3), for the various materials studied.

Table 1 summarises the mechanical properties assumed for the HAZ and the values of yield stress mismatch ratio $\left(M_{\mathrm{YS}}=Y_{0}^{\mathrm{HAZ}} / Y_{0}^{\mathrm{WM}}\right)$ and tensile strength mismatch ratio $\left(M_{\mathrm{TS}}=Y_{\mathrm{TS}}^{\mathrm{HAZ}} / Y_{\mathrm{TS}}^{\mathrm{WM}}\right)$ relative to the WM. In the text, the term undermatch is used if the mismatch parameters $M<1$, evenmatch if $M \cong 1$ and overmatch if $M>1$. By analysing the values in the table and the curves in Fig. 1, it is possible to understand the different types of mismatch conditions studied in this work. In all situations the HAZ is undermatched relatively to the yield stress of the WM $\left(M_{\mathrm{YS}}<1\right)$, but various types of mismatched conditions are considered relative to the maximum tensile strength $\left(M_{\mathrm{TS}}\right.$, Table 1$)$. 


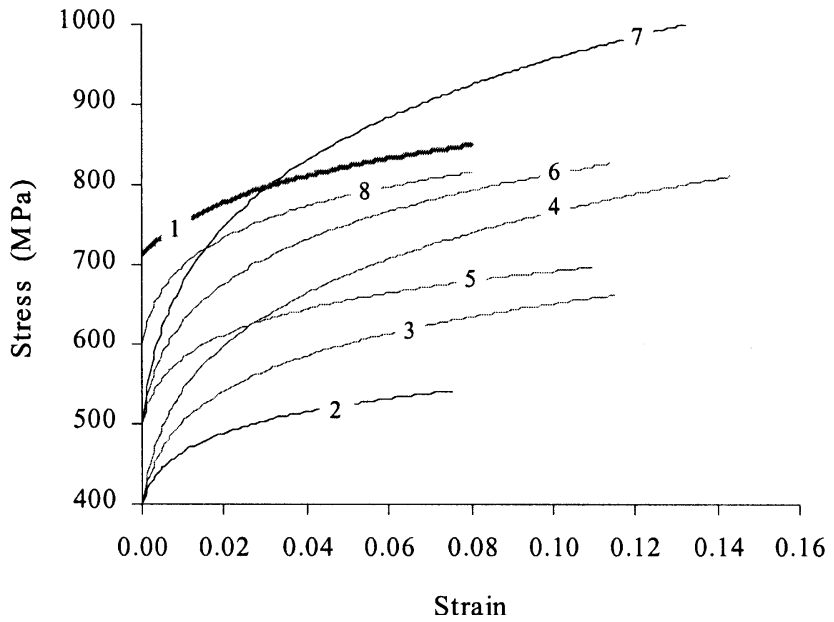

$1-\mathrm{Y}_{0}^{\mathrm{ADJ}}=700 \mathrm{MPa}, n=0.08$

$2-\mathrm{Y}_{0}{ }^{\mathrm{HAZ}}=400 \mathrm{MPa}, n=0.08$

$3-\mathrm{Y}_{0}{ }^{\mathrm{HAZ}}=400 \mathrm{MPa}, n=0.12$

$4-\mathrm{Y}_{0}{ }^{\mathrm{HAZ}}=400 \mathrm{MPa}, n=0.16$

$5-\mathrm{Y}_{0}{ }^{\mathrm{HAZ}}=500 \mathrm{MPa}, n=0.08$

$6-\mathrm{Y}_{0}{ }^{\mathrm{HAZ}}=500 \mathrm{MPa}, n=0.12$

$7-\mathrm{Y}_{0}{ }^{\mathrm{HAZ}}=500 \mathrm{MPa}, n=0.16$

$8-\mathrm{Y}_{0}{ }^{\mathrm{HAZ}}=600 \mathrm{MPa}, n=0.08$

Fig. 1. Stress-strain curves for the various materials considered in the study. The grey curve corresponds to the mechanical behaviour of the adjacent materials (BM and $\left.\mathrm{WM}, Y_{0}^{\text {adj }}=700 \mathrm{MPa}, n=0.08\right)$ and the black curves represent the hypothetical properties considered for the HAZ (Table 1).

\subsection{Finite element modelling}

Three different material domains corresponding to the WM, HAZ and BM compose the finite element meshes used in this research, as is shown in Fig. 2. Specimens with deep cracks $(a / W=0.5$, Fig. 2$)$ and

Table 1

Material properties of the HAZ and stress mismatch ratios: yield stress mismatch $\left(M_{\mathrm{YS}}=Y_{0}^{\mathrm{HAZ}} / Y_{0}^{\mathrm{WM}}\right)$ and tensile strength mismatch $\left(M_{\mathrm{TS}}=Y_{\mathrm{TS}}^{\mathrm{HAZ}} / Y_{\mathrm{TS}}^{\mathrm{WM}}\right)$

\begin{tabular}{|c|c|c|c|c|c|c|c|}
\hline$Y_{0}^{\mathrm{ZTA}}$ & & $400 \mathrm{MPa}$ & & & $500 \mathrm{MPa}$ & & $600 \mathrm{MPa}$ \\
\hline$n$ & 0.08 & 0.12 & 0.16 & 0.08 & 0.12 & 0.16 & 0.08 \\
\hline$M_{\mathrm{YS}}$ & & $\begin{array}{l}0.57 \\
\text { undermatch }\end{array}$ & & & $\begin{array}{l}0.71 \\
\text { undermatch }\end{array}$ & & $\begin{array}{l}0.8 \\
\text { undermatch }\end{array}$ \\
\hline$M_{\mathrm{TS}}$ & $\begin{array}{l}0.65 \\
\text { undermatch }\end{array}$ & $\begin{array}{l}0.79 \\
\text { undermatch }\end{array}$ & $\begin{array}{l}0.98 \\
\text { evenmatch }\end{array}$ & $\begin{array}{l}0.81 \\
\text { undermatch }\end{array}$ & $\begin{array}{l}0.99 \\
\text { evenmatch }\end{array}$ & $\begin{array}{l}1.23 \\
\text { overmatch }\end{array}$ & $\begin{array}{l}0.97 \\
\text { evenmatch }\end{array}$ \\
\hline
\end{tabular}

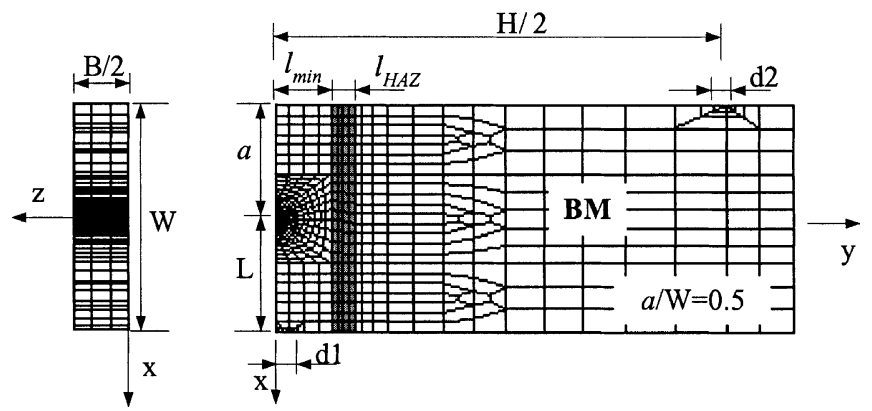

Fig. 2. Finite element mesh used in the numerical simulation of the three-point bend tests of deep crack specimens. $a$ represents the crack depth and $L$ the ligament length. The finite element discretisation was performed using 20-node hexahedron elements. 
shallow cracks $(a / W=0.15)$ located in the WM centreline were simulated. The bending test was simulated imposing displacements $(\Delta)$ on the $x$-direction to the nodes located at $\left(y<d_{1}, x=L\right)$, and restricting the movement in the same direction of the nodes over segment $d_{2}$ in $x=-a$. During these numerical simulations, the movement in the $z$-direction of the nodes located in the $z=0$ and $B / 2$ planes was restricted. This requirement insures that a plane strain state prevails at the crack tip, simulating the most severe conditions for fracture [4].

Several HAZ and WM widths were considered in the numerical simulations. In Fig. $2, l_{\mathrm{HAZ}}$ is the HAZ width and $l_{\min }$ represents the distance from the crack tip to the soft zone, which is equal to one half of the WM width $\left(l_{\min }=l_{\mathrm{WM}} / 2\right)$. The different samples are identified using simple codes of the form HAZXWMY, where $X$ and $Y$ represent the HAZ and WM widths, respectively. For example, a sample for which $l_{\mathrm{HAZ}}=2 \mathrm{~mm}$ and $l_{\mathrm{WM}}=10 \mathrm{~mm}$ is identified through the code HAZ2WM10.

Finally, the TPB test of homogeneous samples with the same mechanical properties of the WM was also simulated. The results obtained with these tests were adopted as the reference behaviour, since the main purpose of this work was to study the crack driving force variation in the weld zone as a function of the HAZ softening.

\section{Results and discussion}

In the study of fracture problems, Rice's $J$ integral [5] is a useful parameter for quantifying the global load applied to a crack under different specimen characteristics. In this work, the $J$ integral was calculated using the equivalent domain integral method [6-9]. As expected for incremental plasticity [10,11] in all simulations, it was observed that the computed $J$ integral is path-independent outside the finitely deformed zone at the crack tip. For the weld geometries considered in this study, the $J$ integral, which was computed along contours remote from the crack, was used as global loading parameter to compare results from the different specimens.

\subsection{Samples with different $H A Z$ widths $\left(l_{H A Z}\right)$}

The graphs in Figs. 3 and 4 show the $J-\Delta$ curves obtained in the TPB test of homogeneous and welded samples (HAZ2WM10, HAZ5WM10, HAZ8WM10). These results correspond to the welds with HAZ yield stress $\left(Y_{0}^{\mathrm{HAZ}}\right)$ of 400,500 and $600 \mathrm{MPa}$ and $n^{\mathrm{HAZ}}=0.08$. In all simulations, the load was increased until a total displacement $(\Delta)$ of $0.6 \mathrm{~mm}$ was reached. For specimens with the most severe undermatch conditions in the HAZ $\left(Y_{0}^{\mathrm{HAZ}}=400 \mathrm{MPa}, n^{\mathrm{HAZ}}=0.08\right)$ the $J-\Delta$ curves are plotted until a total displacement $\Delta=1 \mathrm{~mm}$ is attained, in order to verify if any change in the crack driving force exists with progressive strain hardening of the HAZ.

By analysing the graphs in Fig. 3, where the results obtained for the samples with deep cracks $(a / W=0.5)$ are presented, it is possible to conclude, that the curves for the welded samples are very close to the WM homogeneous results until $\Delta=0.6 \mathrm{~mm}$. The exception to this is in situations with the most severe undermatch conditions in the $\mathrm{HAZ}\left(Y_{0}^{\mathrm{HAZ}}=400 \mathrm{MPa}\right)$, for which it is possible to observe some drop in the $J$ values since $\Delta=0.4 \mathrm{~mm}$. By comparing the results relative to the samples with different HAZ widths (HAZ2, HAZ5, HAZ8 samples), it is possible to conclude that the crack driving force is independent of the HAZ width, since the curves corresponding to the different samples are very close, at least for small displacements.

The results in Fig. 4, relative to samples with shallow cracks $(a / W=0.15)$, show a different trend. In fact, when the HAZ width is larger than $2 \mathrm{~mm}$ for the most severe yield stress undermatch situations, it is possible to observe a severe drop in the $J$ curves relatively to the WM homogeneous sample curve, since $\Delta=0.3 \mathrm{~mm}$. When the HAZ have only $2 \mathrm{~mm}$ width, the $J-\Delta$ curve comes very close to the homogeneous 

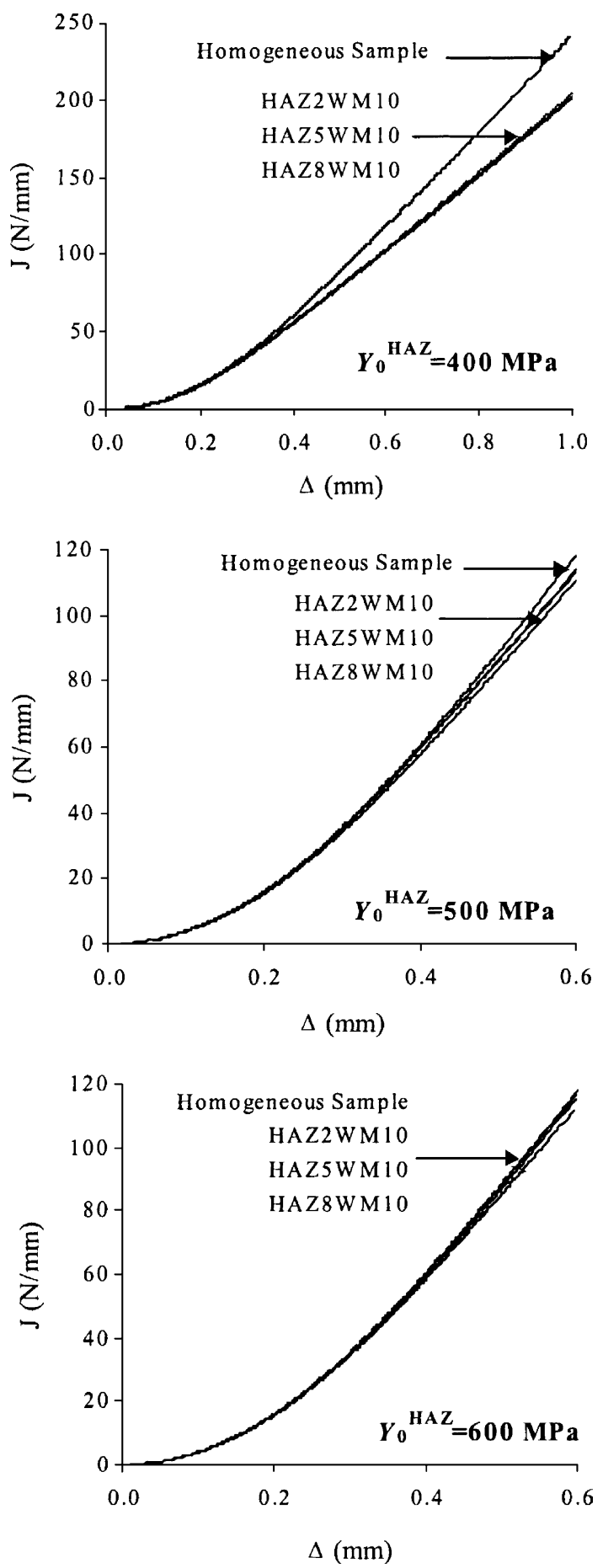

Fig. 3. $J-\Delta$ curves for samples with deep cracks $(a / W=0.5)$, various HAZ widths $\left(l_{\mathrm{HAZ}}=2,5\right.$ and $\left.8 \mathrm{~mm}\right)$ and $l_{\mathrm{WM}}=10 \mathrm{~mm}$. The results were obtained for three different yield stress values of the $\mathrm{HAZ}\left(Y_{0}^{\mathrm{HAZ}}=400,500\right.$ and $\left.600 \mathrm{MPa}\right)$ and considering the same value of the hardening coefficient $n^{\mathrm{HAZ}}=0.08$ in all the simulations. 

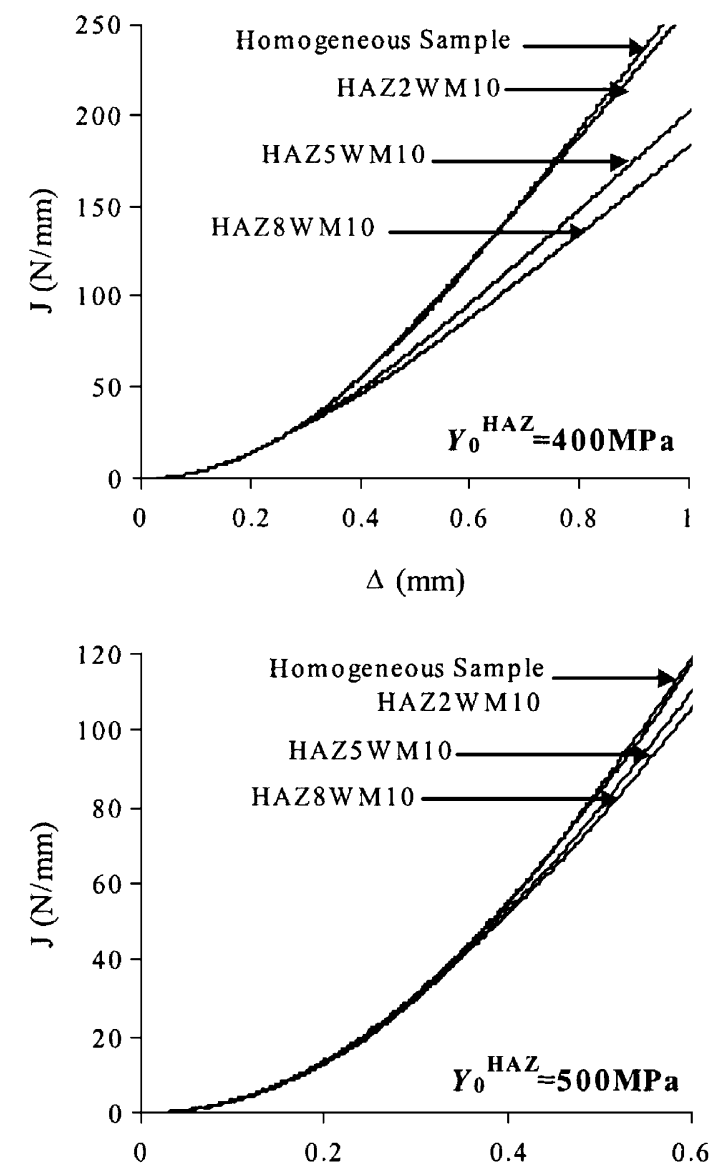

$\Delta(\mathrm{mm})$

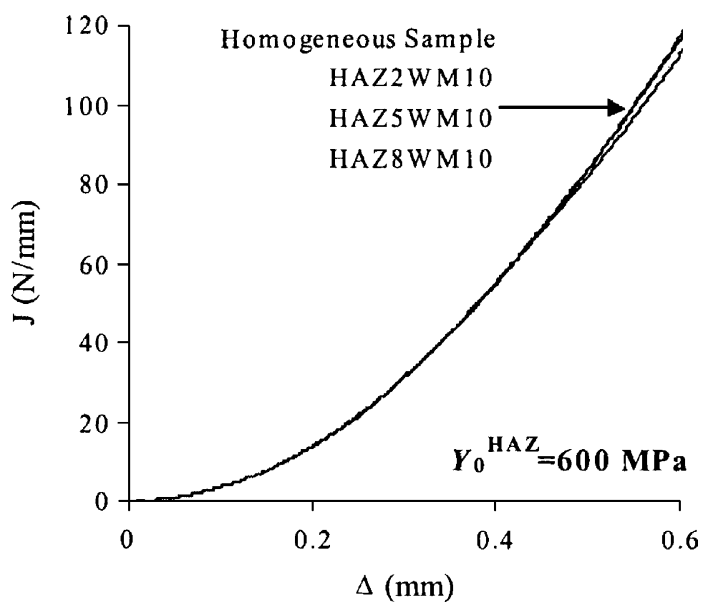

Fig. 4 . $J-\Delta$ curves for samples with shallow cracks $(a / W=0.15)$, various HAZ widths $\left(l_{\mathrm{HAZ}}=2,5\right.$ and $\left.8 \mathrm{~mm}\right)$ and $l_{\mathrm{WM}}=10 \mathrm{~mm}$. The results were obtained for three different yield stress values of the $\mathrm{HAZ}\left(Y_{0}^{\mathrm{HAZ}}=400,500\right.$ and $\left.600 \mathrm{MPa}\right)$ and considering the same value of the hardening coefficient $n^{\mathrm{HAZ}}=0.08$ in all the simulations. 
one, independently of the mismatch values. This shows some influence of the HAZ width on the crack tip loading for shallow crack specimens.

In deep cracked specimens, the weakest section of the specimen is the part containing the crack, making it difficult for the spreading of plastic deformation to the HAZ, unless severe HAZ undermatching exists. The cracked cross section of shallow cracked specimens is more resistant than that of the deep cracked specimens, and the load transfer to the HAZ is more effective resulting in larger plastic deformation in this zone. In this case, the HAZ width assumes some importance. If the plastic deformation in this zone is significant, the strain hardening exponent of the HAZ may be relevant.

The $J-\Delta$ curves obtained during the TPB test of the HAZ5WM10 samples are plotted in Figs. 5 and 6. These consider two yield stress mismatch values $\left(Y_{0}^{\mathrm{HAZ}}=400\right.$ and $\left.500 \mathrm{MPa}\right)$, and different values of the strain hardening exponent of the HAZ $\left(n^{\mathrm{HAZ}}=0.08,0.12,0.16\right)$, for specimens with deep and shallow cracking. By analysing the figures, it is possible to conclude that there is almost no influence of the hardening of the HAZ on the crack driving force, since the different curves are almost superposed, mainly, for low imposed displacements $\Delta$. Once more, shallow cracked specimens are more influenced by the mismatching due to their better capacity to transfer load, and consequently deformation, to the HAZ.
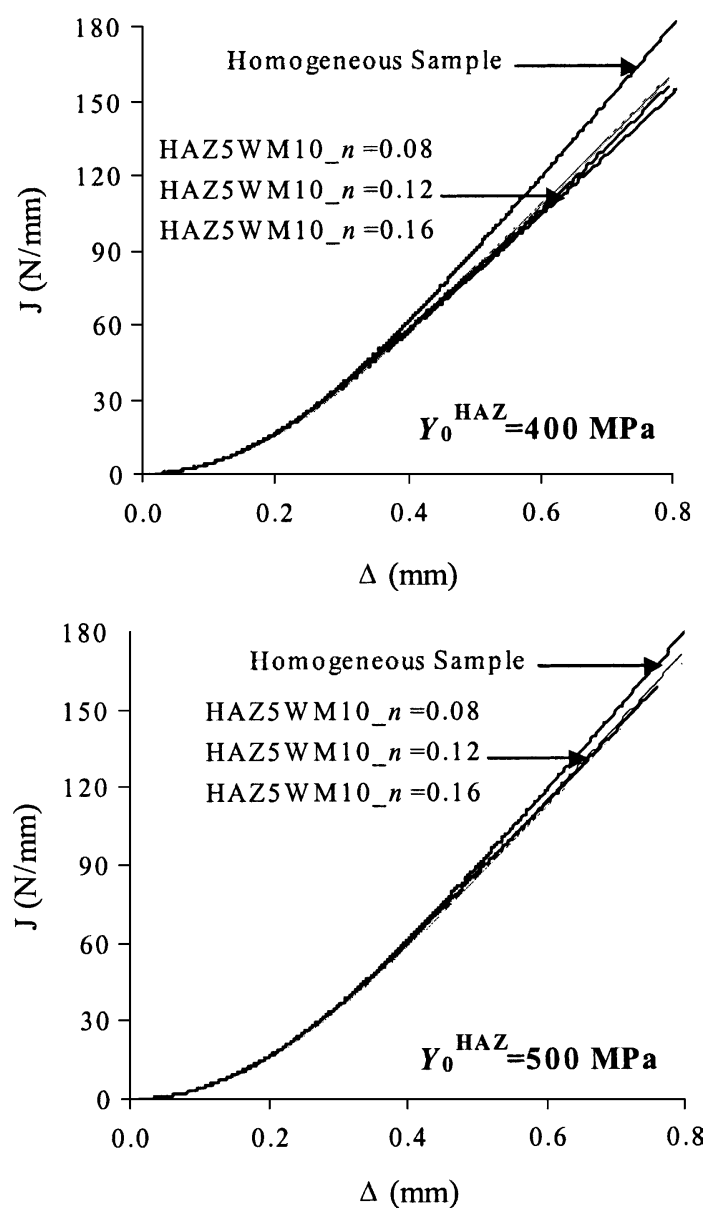

Fig. 5. $J-\Delta$ curves for the samples HAZ5WM10 having different yield strength mismatch factors and strain hardening exponents $\left(n^{\text {HAZ }}=0.08,0.12\right.$ and 0.16$)$. Deep crack specimens $(a / W=0.5)$. 

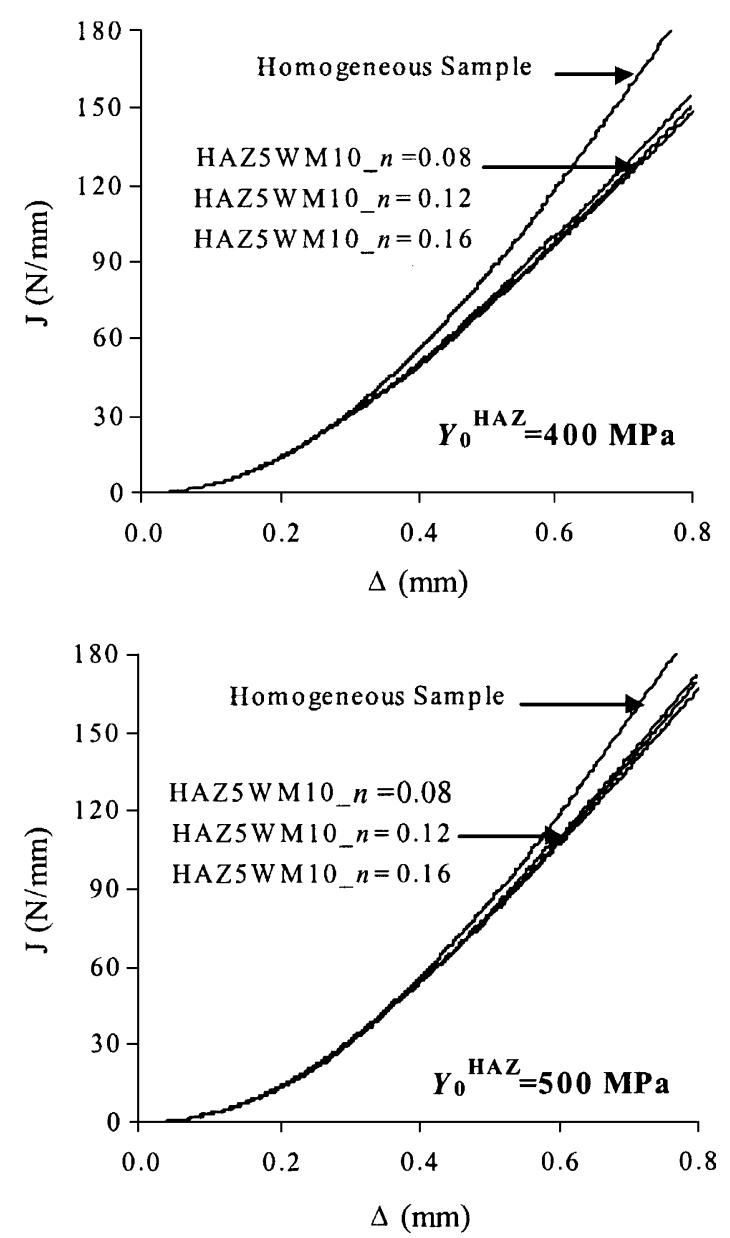

Fig. 6. $J-\Delta$ curves for the samples HAZ5WM10 having different yield strength mismatch factors and strain hardening exponents $\left(n^{\mathrm{HAZ}}=0.08,0.12\right.$ and 0.16$)$. Shallow crack specimens $(a / W=0.15)$.

\subsection{Samples with different $W M$ widths $\left(l_{W M}\right)$}

The variation of the crack driving force, analysed through the $J-\Delta$ curves, was also studied as a function of the WM width, more precisely, as a function of the distance of the crack tip to the WM/HAZ interface $\left(l_{\min }=l_{\mathrm{WM}} / 2\right)$. The $J-\Delta$ curves for specimens with $l_{\mathrm{WM}}=6,8$ and $10 \mathrm{~mm}$ and $\mathrm{HAZ}$ widths equal to 2 and 5 $\mathrm{mm}$ are shown in Fig. 7 for the samples with deep cracks, and in Fig. 8 for the samples with shallow cracks. Since the previous results show that the crack driving force is essentially conditioned by the yield stress mismatch $\left(M_{\mathrm{YS}}\right)$ between the WM and HAZ, the numerical results presented in Figs. 7 and 8 were obtained considering different $\mathrm{HAZ}$ yield stress values $\left(Y_{0}^{\mathrm{HAZ}}=400,500\right.$ and $\left.600 \mathrm{MPa}\right)$, and the same value for the hardening coefficient $n^{\mathrm{HAZ}}=0.08$.

Fig. 7, which is relative to samples with deep cracks, shows that the $J$ values decrease relatively to the homogeneous sample $J$ values when the crack tip approaches the WM/HAZ interface (WM8 and WM6 samples), mainly in the high HAZ undermatch condition. It is also possible to observe that the $J$ variation is almost independent of the HAZ width (results are close for HAZ2 and HAZ5 samples). By analysing the 

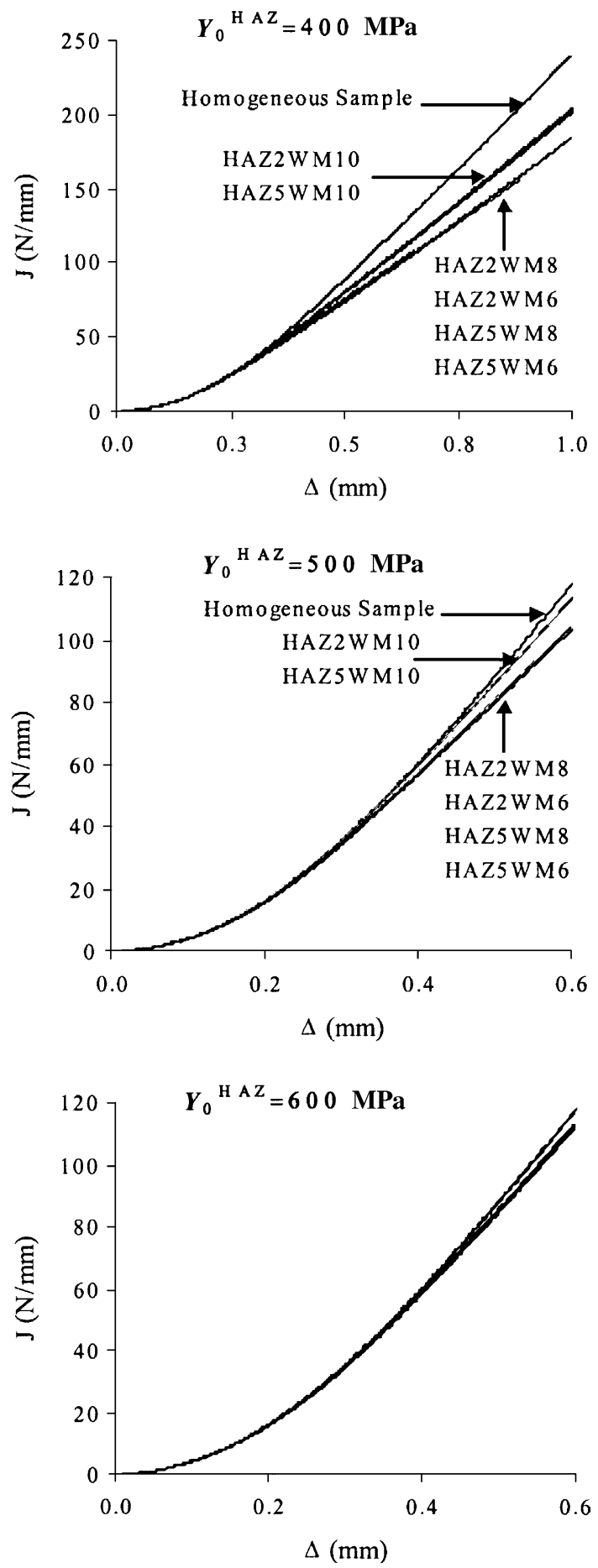

Fig. 7. $J-\Delta$ curves for samples with deep cracks $(a / W=0.5)$, various $\mathrm{HAZ}\left(l_{\mathrm{HAZ}}=2,5\right.$ and $\left.8 \mathrm{~mm}\right)$ and $\mathrm{WM}$ widths $\left(l_{\mathrm{WM}}=6,8\right.$ and 10 $\mathrm{mm})$. The results were obtained for three different yield stress values of the HAZ $\left(Y_{0}^{\mathrm{HAZ}}=400,500\right.$ and $\left.600 \mathrm{MPa}\right)$ and considering the same value of the hardening coefficient $n^{\mathrm{HAZ}}=0.08$ in all the simulations. 

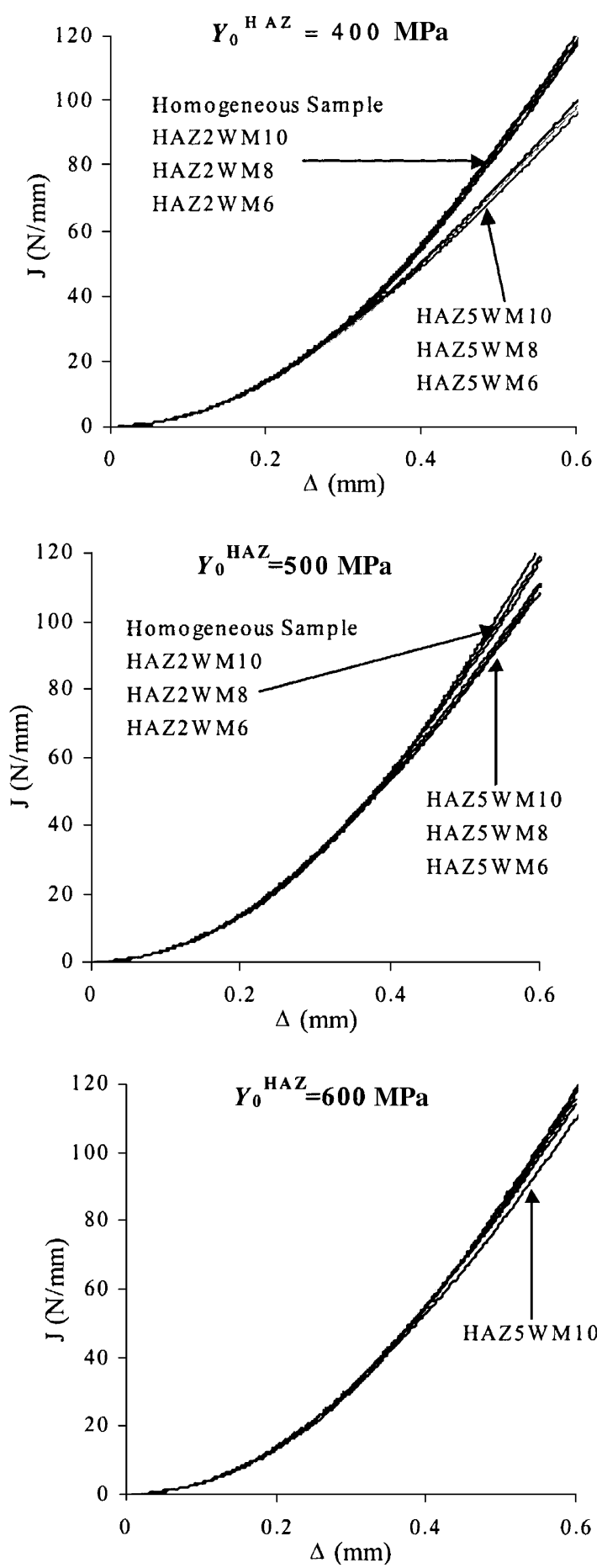

Fig. 8. $J-\Delta$ curves for samples with shallow cracks $(a / W=0.15)$, various $\operatorname{HAZ}\left(l_{\mathrm{HAZ}}=2,5\right.$ and $\left.8 \mathrm{~mm}\right)$ and WM widths $\left(l_{\mathrm{WM}}=6,8\right.$ and $10 \mathrm{~mm}$ ). The results were obtained for three different yield stress values of the $\mathrm{HAZ}\left(Y_{0}^{\mathrm{HAZ}}=400,500\right.$ and $\left.600 \mathrm{MPa}\right)$ and considering the same value of the hardening coefficient $n^{\mathrm{HAZ}}=0.08$ in all the simulations. 


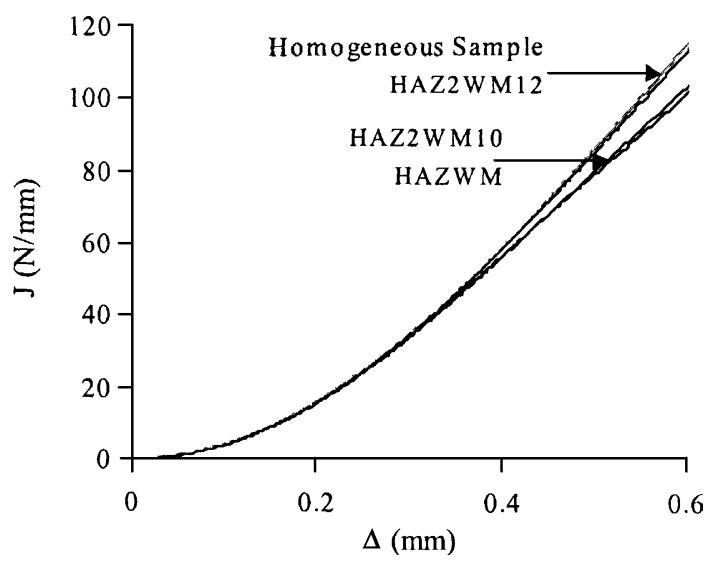

Fig. 9. $J-\Delta$ curves obtained with deep cracked samples: HAZWM $\left(l_{\mathrm{HAZ}}=\infty, l_{\mathrm{WM}}=10 \mathrm{~mm}\right), \mathrm{HAZ} 2 \mathrm{WM} 12\left(l_{\mathrm{HAZ}}=2, l_{\mathrm{WM}}=12 \mathrm{~mm}\right)$, $\operatorname{HAZ2WM10}\left(l_{\mathrm{HAZ}}=2, l_{\mathrm{WM}}=10 \mathrm{~mm}\right)$ and $\mathrm{WM}$ homogeneous sample. HAZ material $\left(Y_{0}^{\mathrm{HAZ}}=400 \mathrm{MPa}, n^{\mathrm{HAZ}}=0.08\right)$.

results relative to samples with shallow cracks, presented in Fig. 8, it is possible to conclude that the drop in the $J-\Delta$ curves is independent of the distance $l_{\min }$ (results are close for WM6, WM8 and WM10 samples), being mainly affected by the HAZ width.

The results obtained with the deep crack samples $(a / W=0.5)$, suggest that the influence of the HAZ softening on the fracture behaviour of the specimens is essentially conditioned by the amplitude of the yield stress mismatch $\left(\sigma_{0}^{\mathrm{HAZ}} / \sigma_{0}^{\mathrm{WM}}\right)$, and by the distance of the crack tip to the soft zone $\left(l_{\min }\right)$, independently of the width of this zone. In order to verify if the crack driving force is effectively independent of the soft zone width, and for which values of $l_{\mathrm{WM}}$ (or $l_{\min }$ ) this influence disappears, new simulations were performed using two new types of meshes. The first mesh represents a weld with $l_{\mathrm{HAZ}}=2 \mathrm{~mm}$ and $l_{\mathrm{WM}}=12 \mathrm{~mm}$ and will be identified by the code HAZ2WM12. The other mesh represents a weld with an infinite HAZ width $\left(l_{\mathrm{HAZ}}=\infty\right)$ and $l_{\mathrm{WM}}=10 \mathrm{~mm}(\mathrm{WM} / \mathrm{HAZ}$ bi-material system) identified by the code WMHAZ. The results corresponding to these new simulations are presented in Fig. 9, together with the results of the WM homogeneous sample and HAZ2WM10. By comparing the curves, it is possible to observe that the results obtained with the sample HAZ2WM12 approach the results registered in the WM homogeneous sample. This proves that when the distance from the crack tip to the soft zone increases, the influence of the HAZ on the crack driving force vanishes. By comparing the results of the samples HAZ2WM10 $\left(l_{\mathrm{HAZ}}=2 \mathrm{~mm}\right)$ and HAZWM $\left(l_{\mathrm{HAZ}}=\infty\right)$, it is also possible to confirm that the crack driving force is independent of the soft zone width, since the curves for both samples are very close.

\section{Conclusions}

A large variety of weld dimensions and mismatch conditions of the heat affected zone relative to the welding metal were addressed in this investigation, in order to investigate the influence of the occurrence of HAZ softening on the fracture resistance of welds with cracked WM.

The results presented in Figs. 3 and 5 are relative to samples with deep cracks. They show that only a strong yield stress undermatch of the HAZ relative to the $\mathrm{WM}\left(M_{\mathrm{YS}}=0.57\right)$ can originate a drop in the $J$ values of the weld samples relative to those registered in a sample of homogeneous WM, when loaded up to the same imposed displacement value (4). This occurs even when the soft HAZ structure has only $2 \mathrm{~mm}$ in width, and is more pronounced when the distance of the crack tip to the HAZ is smaller. It was also possible to conclude that the crack driving force is independent of the HAZ width (Fig. 9). 
On the other hand, the results obtained for the samples with shallow cracks (Figs. 4 and 6) show an opposite trend. The drop in the $J-\Delta$ curves is clearly a function of the yield stress undermatch value, but only occurs when the HAZ width is greater than $2 \mathrm{~mm}$. The drop in the $J-\Delta$ curves relative to homogeneous sample results is independent of the weld metal width. When the HAZ width is large, the drop in $J-\Delta$ curves of shallow crack specimens is more pronounced than the one registered in deep crack samples.

\section{Acknowledgements}

The authors wish to acknowledge the sponsorship of Fundação para a Ciência e a Tecnologia (FCTMCT).

\section{References}

[1] Thaulow C, Paauw AJ, Hauge M, Toyoda M, Minami F. Fracture property of HAZ-notched weld joint with mechanical mismatching-Part II. In: Schwalbe K-H, Koçak M, editors. Mis-matching of welds, ESIS 17. London: Mechanical Engineering Publications; 1994. p. 417-32.

[2] Wojnowski D, Oh YK, Indacochea JE. Metallurgical assessment of the softened HAZ region during multipass welding. J Manuf Sci Engng (ASME) 2000;122(2):310-5.

[3] Menezes LF, Fernandes JV, Rodrigues DM. Numerical simulation of tensile tests of pre-strained sheets. Mat Sci Engng A 1999;264(1-2):130-8.

[4] Hutchinson JW. Fundamentals of the phenomenological theory of non-linear fracture mechanics. ASME J Appl Mech 1983;50(4B):1042-51.

[5] Rice JR. A path independent integral and the approximate analysis of strain concentration by notches and cracks. J Appl Mech 1968;35(2):379-86.

[6] Li FZ, Shih CF, Needleman A. A comparison of methods for calculating energy releases rates. Engng Fract Mech 1985;21(2):40521.

[7] Nikishkov GP, Atluri SN. Calculation of fracture mechanics parameters for an arbitrary three-dimensional crack, by the equivalent domain integral method. Int J Numer Meth Engng 1987;24(9):1801-21.

[8] Shivakumar KN, Raju IS. An equivalent domain integral method for three-dimensional mixed-mode fracture problems. Engng Fract Mech 1992;42(6):935-59.

[9] Schmitt W, Kienzler R. The $J$-integral concept for elastic-plastic material behavior. Engng Fract Mech 1989;32(3):409-18.

[10] Stump DM, Zywicz E. $J$-integral computations in the incremental and deformation plasticity analysis of small-scale yielding. Engng Fract Mech 1993;45(1):61-77.

[11] Shih CF, German MD. Requirements for a one parameter characterization of crack tip fields by the HRR singularity. Int J Fract 1981;17(1):27-43. 